\title{
Optical and Electrical Properties of ZnO Nanorods at different Temperatures
}

\author{
R.K. Das \\ Dept. of Physics, Charuchandra College (University of Calcutta), Kolkata, India \\ *Corresponding Author: rkdas_171171@rediffmail.com
}

Available online at: www.isroset.org

Received: 12/Nov/2017, Revised: 25/Nov/2017, Accepted: 20/Dec/2017, Published: 31/Dec/2017

\begin{abstract}
Here $\mathrm{ZnO}$ (Zinc Oxide) nanorods are synthesized by using hydrothermal process. ZnO nanorods were synthesized on annealed seeded layer by hydrothermal method at different temperatures $50^{\circ} \mathrm{C}, 65^{\circ} \mathrm{C}, 75^{\circ} \mathrm{C}$, and $85^{\circ} \mathrm{C}$. Optical and electrical properties were studied using Diffused Reflectance Spectra analyser (DRS) and current-voltage measurements are done on the prepared $\mathrm{ZnO}$ nanorods thin films. Diffused reflectance occurs when the incident radiation beam is focused on the sample at a particular temperature and the surface of the sample is rough or irregular so that a part of the incident beam is reflected which is considered to be diffuse reflection. Then the back reflected and diffusely scattered light is collected by the detector. The UV spectra analyser shows the absorption peaks appear at $366 \mathrm{~nm}, 367 \mathrm{~nm}, 366 \mathrm{~nm}$ and $369 \mathrm{~nm}$ while growth temperature increases from $50{ }^{\circ} \mathrm{C}$ to $85{ }^{\circ} \mathrm{C}$. Band Gap energy of the sample is also calculated at different temperatures. $\mathrm{ZnO}$ nanorods have huge applications in nanotechnology.
\end{abstract}

Keywords-ZnO, Nanorods, Optical, Electrical Properties, Diffusedr eflectance, QDSSC

\section{INTRODUCTION}

$\mathrm{ZnO}$ nanomaterials have many applications in nanotechnology. These $\mathrm{ZnO}$ nanorods are widely used in electronic devices like solar cells, short wavelength lasers ,chemical sensors etc. It is also suitable material for Quantum Dot Sensitized Solar Cells (QDSSC). There are various methods for synthesizing $\mathrm{ZnO}$ nanorods [1-3]. Cobalt nanoparticles were prepared by using modified Polyol process [4]. One of the method is hydrothermal method which is simple, used at low temperature, has high yield than other methods [5-9]. So in our previous work we have used the hydrothermal process for the growth of $\mathrm{ZnO}$ nanorods on FTO (Flourine doped Tin Oxide) substrates at different temperatures [10]. And in this paper we have investigated optical and electrical properties by diffused reflectance spectra analyzer (DRS) \& I-V measurements are also performed. Diffused reflectance occurs when the incident radiation beam is focused on the sample at a particular temperature and the surface of the sample is rough or irregular so that a part of the incident beam is reflected which is considered to be diffuse reflection. Then the back reflected and diffusely scattered light is collected by the detector.

This paper has been written into four distinct sectionsIntroduction, Experimental procedure, Results and discussions and conclusion. Introduction section gives the brief review of literature related to our present work. Experimental procedure gives how optical and electrical properties were studied using Diffused Reflectance Spectra analyser (DRS) and current-voltage measurements are done on the prepared $\mathrm{ZnO}$ nanorods thin films. Results and discussion section gives the results showing optical and electrical properties of our sample. Conclusion part gives the major conclusion drawn from our results.

\section{Experimental Procedure}

When the electromagnetic radiation in the UV/NIR (near infra red) wavelength range interacts with a sample then the radiation is either absorbed, transmitted, reflected or scattered. UV/NIR spectrometers are used here to measure transmittance. Reflectance spectroscopy is used for those samples for which we cannot analyze by transmission measurements. There are two types of Reflectance measurements- internal and external reflectance. Attenuated total reflection (ATR) is generally used for internal reflectance measurements when the beam of radiation passes through an ATR element ( such as crystal) contact with the sample. For the measurement of external reflectance, the beam of incident radiation is reflected directly from the sample surface [11-13]. With the help of spectrometer it is possible to measure reflected radiation which may be either specular or diffuse. An Integrating sphere when combine with spectrometer can be used for collection of reflected radiation from the sample and used for the measurement of diffuse reflectance. This is shown in fig.1(a-d). Diffuse reflectance is the external reflectance measurements which is excellent for nanomaterials (both powdered as well as 
crystalline forms) in different spectral ranges. External reflectance are of two types - diffuse and specular. In the case of specular reflectance, energy from incident beam is reflected from the plane surface of sample like mirror in all possible directions. And if the reflectance light is reflected from rough and irregular surface and only part of incident beam is reflected then this is called diffuse reflectance. This has been observed in many samples like fibres, textiles , powders which gives diffusely reflected spectra [11-13]. Some powders are analysed by diffused reflectance. Specular reflectance is observed in plane surface as shown in fig.1. The optical transition in semiconductor are taken place by direct and indirect transition. The value of optical band-gap energy can be calculated as

Band Gap Energy $(E)=h C / \lambda$

$\mathrm{h}=$ Planks constant $=6.626 \times 10^{-34}$ Joules sec

$\mathrm{C}=$ Speed of light $=3.0 \times 10^{8}$ meter $/ \mathrm{sec}$

So Band Gap Energy of $\mathrm{ZnO}$ samples are calculated at different temperatures and shown in table1. And current voltage characteristics have been shown in fig 6 .

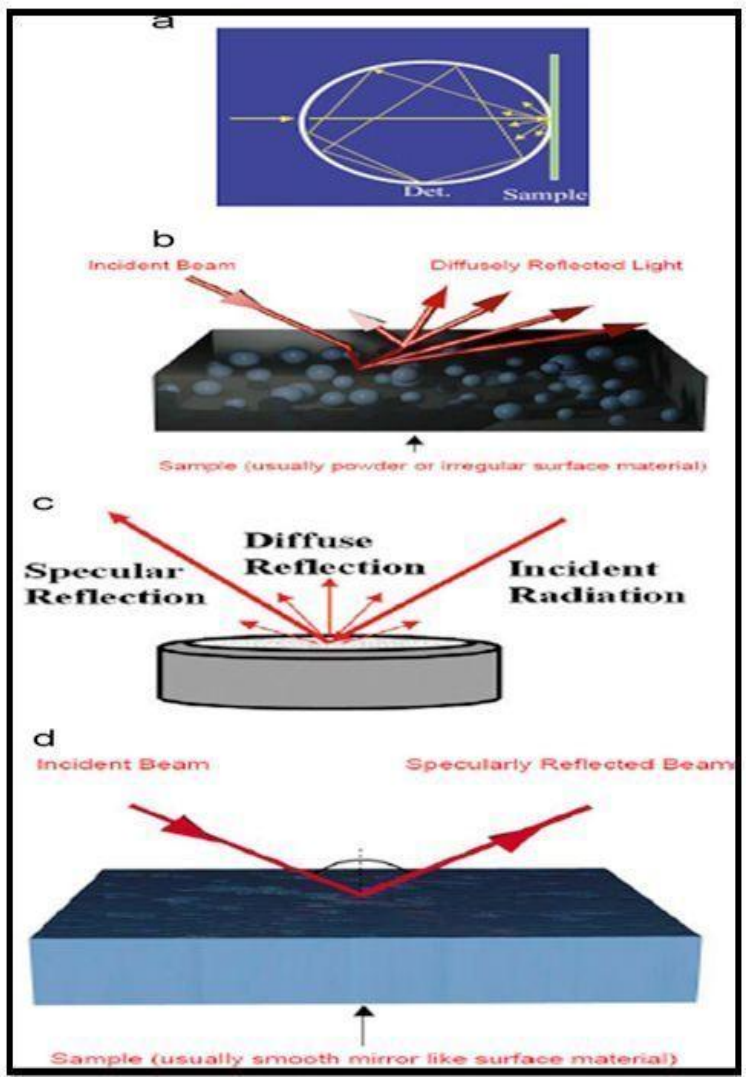

Fig1. a) Shows how light enter the sphere

b) Shows the diffused reflected light

c) Shows the incident radiation, diffuse reflection and specular reflection

d) Shows the incident beam and specular reflection.

\section{RESULTS AND DISCUSSION}

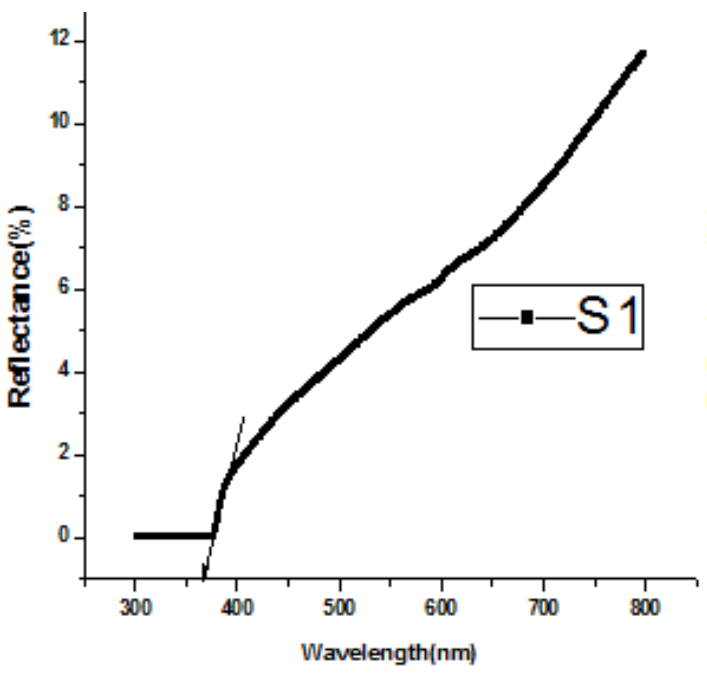

Fig2: Wavelength vs. diffused reflectance graph at $50^{\circ} \mathrm{C}$

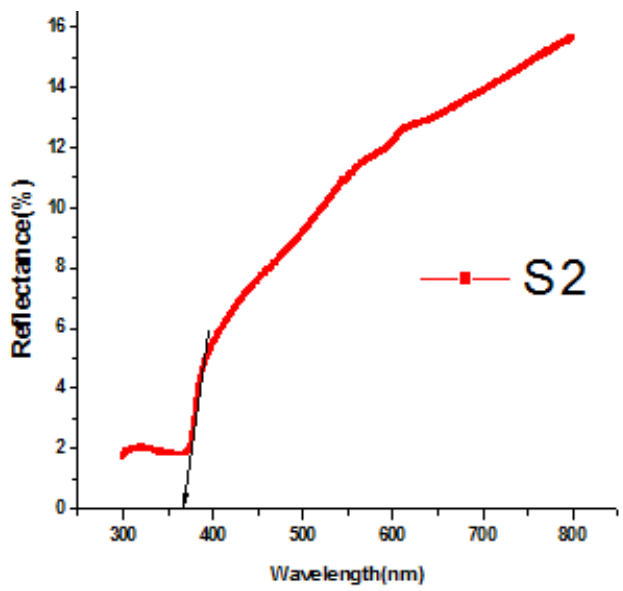

Fig 3: Wavelength vs. diffused reflectance graph at $65^{\circ} \mathrm{C}$

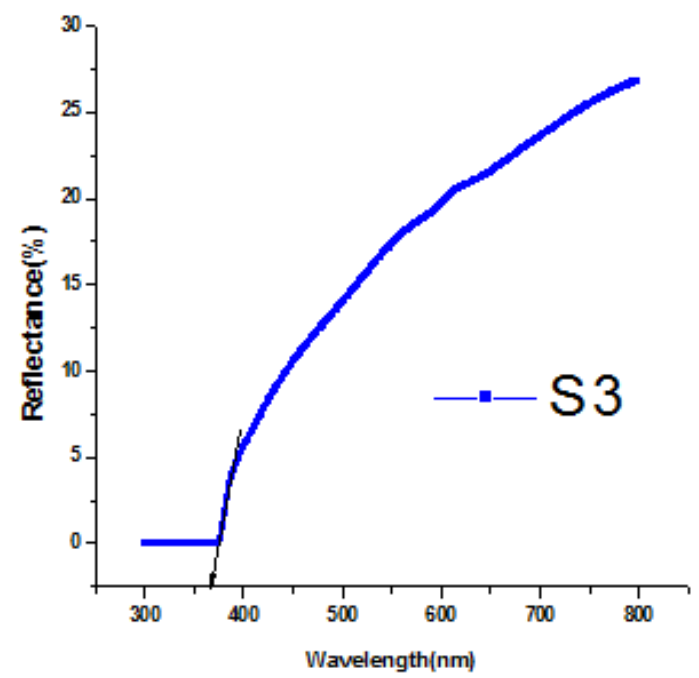

Fig 4: Wavelength vs. diffused reflectance graph at $75^{\circ} \mathrm{C}$ 


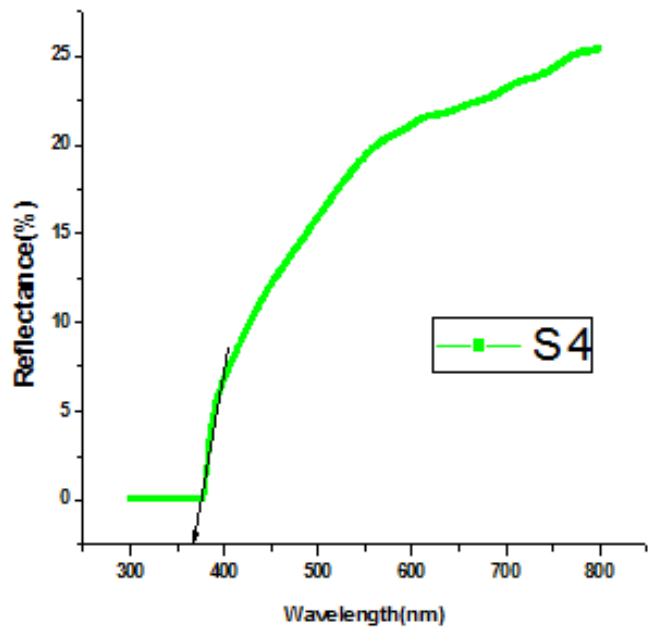

Fig5: Wavelength vs. diffused reflectance graph at $85^{\circ} \mathrm{C}$

$\mathrm{ZnO}$ nanorods are synthesized by hydrothermal process in our previous paper at temperatures $50^{\circ} \mathrm{C}, 65^{\circ} \mathrm{C}, 75^{\circ} \mathrm{C}$ and $85^{\circ}$ C.

Fig. 2 to Fig. 5 shows the plots of the diffused reflectance for $\mathrm{ZnO}$ nanorods at above mentioned temperatures. This shows the diffused reflectance plots of different samples under different temperatures. In details theoretical band gap of $\mathrm{ZnO}$ is $3.37 \mathrm{eV}$ which is good agreement with the determined value from diffused reflectance calculation. The details are given in the table 1 .

TABLE 1. The obtained values of band gap energy for different samples of $\mathrm{ZnO}$

\begin{tabular}{|l|l|l|l|}
\hline \multirow{7}{*}{$Z \mathbf{Z n O}$} & $\begin{array}{l}\text { SAMPLE } \\
\text { NO. }\end{array}$ & $\begin{array}{l}\text { ABSORPTION } \\
\text { EDGE }(\text { nm })\end{array}$ & $\begin{array}{l}\text { ENERGY } \\
\text { BAND } \\
\text { GAP E } \\
(\text { eV })\end{array}$ \\
\cline { 2 - 4 } & 1 & 366 & 3.39 \\
\cline { 2 - 4 } & 2 & 367 & 3.38 \\
\cline { 2 - 4 } & 3 & 366 & 3.39 \\
\cline { 2 - 4 } & 4 & 369 & 3.36 \\
\hline
\end{tabular}

The CURRENT vs VOLTAGE characteristics of the thin films :-

The dark and UV-illuminated $\mathrm{I}-\mathrm{V}$ characteristics are shown in Fig.6. Both the linear and non-linear behaviour in the I-V curves were observed in the $\mathrm{ZnO}$ thin films in dark and under UV-illumination respectively. The current at a given voltage for the films under UV-illumination is higher than that of under dark condition. This indicates that the UV-illumination increases the production of electron-hole pairs. The effect of the light on the films shows that the obtained $\mathrm{ZnO}$ thin films can be used as a photovoltaic material. The I-V characteristics of the films in dark and under UVillumination show that the hydrothermally grown $\mathrm{ZnO}$ thin films are sensitive to UV-light. It is thought that because of these properties, $\mathrm{ZnO}$ thin films can be used as an excellent material in photovoltaic applications.

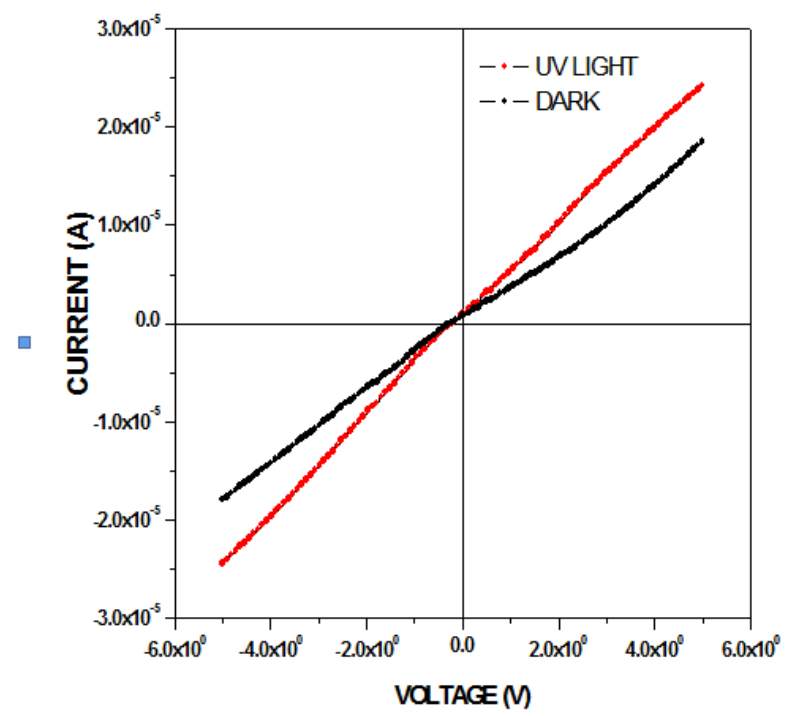

Fig 6. Showing the current vs voltage curve.

\section{CONCluSion}

In summary, $\mathrm{ZnO}$ micro and nanostructure needles were synthesized by hydrothermal solution technique. $\mathrm{ZnO}$ rods grown at different temperatures $50^{\circ} \mathrm{C}, 65^{\circ} \mathrm{C}, 75^{\circ} \mathrm{C}$, and $85^{\circ} \mathrm{C}$ in our previous paper. Here optical and electrical properties were studied using Diffused reflectance spectra analyser (DRS) and current-voltage measurements are done on the prepared $\mathrm{ZnO}$ nanorods thin films. It is found that the dimension of $\mathrm{ZnO}$ nanorods changed with different temperature. The UV spectra analyses show the absorption peaks appear at $366 \mathrm{~nm}, 367 \mathrm{~nm}, 366 \mathrm{~nm}$ and $369 \mathrm{~nm}$ while growth temperature increases from $50^{\circ} \mathrm{C}$ to $85^{\circ} \mathrm{C}$.

\section{ACKNOWLEDGMent}

I am thankful to Department of Physics, Charuchandra College, University of Calcutta for giving me support.

\section{REFERENCES}

[1] M.H. Huang, Y.Wu, H. Feick, N. Tran, E.Weber, P.Yang, "Catalytic growth of zinc oxide nanowires by vapour transport," Advanced. Materials, vol.13, pp.113-116, 2001.

[2] Y.C. Kong, D.P. Yu, B. Zhang,W. Fang, S.Q. Feng,"Ultravioletemitting $\mathrm{ZnO}$ nanowires synthesized by a physical vapour deposition approach,", Applied Physics Letters, vol.78, pp.407409, 2001

[3] J.-J. Wu, S.-C. Liu, "Low-Temperature and Catalyst-Free Synthesis of Well-Aligned ZnO Nanorods on Si (100),"Advanced Materials, vol.14, pp.215-218, 2002. 
[4] G. Chandraprabha, T. Sankarappa, T. Sujatha, "Structure and magnetic studies of Cobalt Nanoparticles prepared by Modified Polyol Process", International Journal of Scientific Research in Physics and Applied Sciences, vol.5, Issue 4, pp. 17-20, 2017.

[5] C.X. Xu, A. Wei, X.W. Sun, Z.L. Dong, "Aligned ZnO nanorods synthesized by a simple hydrothermal reaction.", Journal of Physics D :Applied Physics, Vol.39, pp. 1690-1693, 2006.

[6] J. Song, S. Baek, S. Lim, "Effect of hydrothermal reaction conditions on the optical properties of ZnO nanorods", Physics.B: Condensed Matter, Vol. 403 ,pp.1960-1963, 2008.

[7] L. Vayssieres, K. Keis, S. Lindquist, A. Hagfedt, "Hydrothermal Synthesis and Properties of Diluted Magnetic Semiconductor Zn ${ }_{1-}$ ${ }_{x} M n_{x}$ O Nanowires", Journal of Physical Chemistry B, Vol. 105, pp.3350-3352, 2001.

[8] B. Liu, C.H. Zeng, "Hydrothermal Synthesis of ZnO Nanorods in the Diameter Regime of $50 \mathrm{~nm}$ ", Journal of American Chemical Society, Vol. 125, pp. 4430-4431, 2003.

[9] Z. Qiu, K.S. Wong, M. Wu, W. Lin, H. Xu, "Microcavity lasing behaviour of oriented hexagonal $\mathrm{ZnO}$ nanowhiskers grown by hydrothermal oxidation", Applied Physics Letters, Vol.84, pp.2739-2741, 2004.

[10] R.K. Das, "Preparation of $\mathrm{ZnO}$ Nanorods by Hydrothermal Process at Different Temperatures", International Journal of Scientific Research in Physics and Applied Sciences, vol.5, Issue 5, pp. 12-15, 2017.

[11] J.-J. Wu, S.-C. Liu, "Catalyst-Free Growth and Characterization of $\mathrm{ZnO}$ Nanorods,",Journal of Physical Chemitry B, Vol.106, pp.9546-9551, 2002.

[12] J. Zhang, L. Sun, H. Pan, C. Liao, C. Yan, "ZnO nanowires fabricated by a convenient route", New Journal of Chemistry, Vol.26, pp.33-34, 2002.

[13] Y. Li, G.W. Meng, L.D. Zhang, F. Phillipp, "Ordered semiconductor $\mathrm{ZnO}$ nanowire. Arrays and their photo luminescence properties", Applied Physics Letters, Vol.76, pp.2011-2014, 2000.

\section{Author Profile}

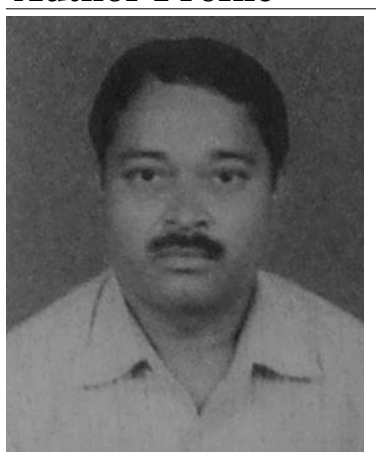

Mr. R.K. Das has completed B.Sc from St. Paul's Cathedral Mission College under university of Calcutta. He has completed M.Sc in physics from Calcutta University. He has been working (Lecturer and Assistant Professor Stage II) with Department of Physics, Charuchandra College, Kolkata which is affililiated to Calcutta University for 15 years. He has 6 research publications and 4 papers have been communicated till now. And his research topic is basically electronics. He has taught Physics for 15 years and basically the topics are Electronics, Quantum Mechanics, Classical Mechanics, Electrodynamics, Magnetism, Thermodynamics, Electromagnetic Theory, Solid State Physics, Relativity. Presently he is continuing in his teacher job 